\title{
(6) OPEN ACCESS \\ Time matters in multiple sclerosis: can early treatment and long-term follow-up ensure everyone benefits from the latest advances in multiple sclerosis?
}

\author{
João J Cerqueira, ${ }^{1,2}$ D Alastair S Compston, ${ }^{3}$ Ruth Geraldes, ${ }^{4}$ Mario M Rosa, ${ }^{5}$ \\ Klaus Schmierer, ${ }^{6}$ Alan Thompson, ${ }^{7}$ Michela Tinelli, ${ }^{8,9}$ Jacqueline Palace ${ }^{4}$
}

1 Life and Health Sciences

Research Institute (ICVS), School of Medicine, University of

Minho, Braga, Portugal ${ }^{2}$ ICVS/3B's, PT Government Associate Laboratory, Braga/ Guimarães, Portugal

${ }^{3}$ Department of Clinical Neurosciences, Cambridge Biomedical Campus, Cambridge, UK

${ }^{4}$ Nuffield Department of Clinical Neurosciences, University of Oxford, Oxford, UK

${ }^{5}$ Faculty of Medicine, University of Lisbon, Lisbon, Portugal

${ }^{6}$ Blizard Institute, Barts and The London School of Medicine and

Dentistry, London, UK

${ }^{7}$ Faculty of Brain Sciences,

University College London,

London, UK

${ }^{8}$ LSE Enterprise, London School

of Economics, London, UK

${ }^{9}$ Personal Social Services

research Unit (PSSRU), London

School of Economics and

Political Science, London, UK

\section{Correspondence to}

Dr Jacqueline Palace, Nuffield

Department of Clinical

Neurosciences, JohnRadcliffe

Hospital, Oxford OX3 9DU, UK

jacqueline.palace@ndcn.ox.

ac.uk

Received 23 October 2017

Revised 2 February 2018

Accepted 22 February 2018

Published Online First

4 April 2018
Check for updates

To cite: Cerqueira JJ, Compston DAS, Geraldes R, et al. J Neurol Neurosurg Psychiatry 2018;89:844-850.

\section{INTRODUCTION}

The management of multiple sclerosis (MS) has been a neurology success story for the past 25 years. Advances in understanding of the disease mechanisms and the dynamic nature of the disease have brought around 12 disease-modifying therapies (DMTs) to market in many countries.

However, treatment is hampered by adverse effects and by limited evidence of efficacy in more advanced 'progressive' MS. Some patients do not receive DMTs for years after diagnosis, or are told medication can no longer help as their disability is worsening. The cost of DMTs is also a significant issue, especially in low-income and middle-income countries.

MS affects an estimated 2.5 million people worldwide, with a higher prevalence and incidence in the northern hemisphere. ${ }^{1}$ Patients with MS now have a longer life expectancy, ${ }^{23}$ in part because of earlier treatment. Accounting for comorbidities such as age-related vascular disease will become increasingly important in patient management. ${ }^{4}$

The Journal of Neurology, Neurosurgery \& Psychiatry brought together a panel of experts on World MS Day 2017 to discuss the importance of time in MS-timing of initiation and withdrawal of disease-modifying treatment, time to consider contributory factors such as vascular disease, and the time and cost burden of MS. This paper, which originated in the round table discussion, reviews the following:

- latest thinking in timing of disease management

- how treatment and prevention of vascular injury may buy additional time for people with MS

- new data about the true economic and social burden of the disease for people with MS and their carers.

\section{TIMING OF DISEASE MANAGEMENT: THE CASE FOR STARTING DISEASE MODIFICATION TREATMENT EARLY}

MS damages the whole brain, and damage begins from the start of the disease. Every system in the brain-myelin, white matter, neurones, axons and blood vessels-is damaged by MS..$^{5-7}$ Brain atrophy, both in the cortex and the white matter, is progressive and accelerates over time. ${ }^{8}$ Evidence from MRI scans shows that even at the earliest stages of MS, people lose brain volume, and that it is lost at the same rate as someone with later stage disease. ${ }^{9}$
Recent painstaking research using donated brain tissue found that people who die with MS have a neuron count 39\% lower than people without MS, ${ }^{10}$ due at least in part to damage to fibre tracts and subsequent retrograde/anterograde neuronal degeneration. ${ }^{11}$ This loss is strongly associated with the thickness of the cortical and deep grey matter, ${ }^{1213}$ which suggests cortical volume measures using MRI that are predictive of clinical outcome indeed reflect neuronal loss. ${ }^{14}$

While repair of brain plaques can be detected in the early stages of MS, the regenerative potential of the brain is limited and becomes less effective with age. ${ }^{15-17}$ Results of trials attempting to induce regeneration have so far not been very promising. ${ }^{18}$

All these suggest that swift action to prevent or slow damage to the brain is crucial. Clinicians must act before the disease causes irreparable damage to the brain, and before the brain's limited mechanisms for repair are damaged. There is increasing consensus about the importance of early intervention to maximise lifelong brain health. ${ }^{19}$

So when should treatment start and what criteria should guide a clinician's decision as to when to offer disease-modifying treatment? Clinicians often think of MS progression in terms of walking ability and judge the progress of MS by performance on tests such as the timed 25-foot walk. However, for people with MS, cognitive health is of major importance and is impaired before walking ability. Cognitive deficit, not walking ability, has the biggest impact on the employment status of people with $\mathrm{MS}^{20}$

Cognition decreases over time with MS, right from the outset. ${ }^{21}$ Even people with radiographically isolated syndrome suggestive of MS may have hidden cognitive deficits. ${ }^{22}$ On the other hand, people with MS and normal cognitive function may also have compromised brain functioning, ${ }^{23}$ putting them at impending risk of collapse. While early structural damage might in many patients preserve overall network efficiency, its continuous accumulation during the course of disease leads to an inevitable decrease in such efficiency (increased or additional recruitment of brain areas and/or altered connectivity between regions). ${ }^{24}$ Importantly, cognitive impairment might not be apparent until brain network efficiency reaches a certain threshold, which seems to be different from individual to individual according to, among other factors, premorbid cognitive reserve. ${ }^{25}$ 
Indeed, evidence shows that children who go on to develop MS in adulthood show evidence of poorer school performance, suggesting that the disease could be affecting cognition 5-10 years before any clinical manifestation can be seen. ${ }^{26}$

If cognitive decline starts so early, we need to begin treating MS with disease-modifying drugs as soon as we are aware of it.

The best long-term evidence that we have, from follow-up studies on participants in early trials of interferon beta, showed a clear improvement in mortality for patients who started the drug 1 or 2 years earlier. ${ }^{27}$ We can also see an impact on disability. Long-term follow-up of early trials of natalizumab showed that, even after 5 years, patients who were in the initial treatment group had a lower Expanded Disability Status Scale (EDSS) score than those who were initially treated with placebo and started active treatment 2 years later. ${ }^{28}$

The impact of treatment may decrease as the disease unfolds in line with the natural history of MS, where we can see that the impact of relapses on disability progression is higher in the earlier stages of the disease. ${ }^{29}$

A recent positive trial of siponimod in secondary progressive MS further suggested that, even in the latter phases, disease duration is a key factor in determining the impact that drugs can make. The study found the effect of siponimod in delaying confirmed disability progression decreased as disease duration increased, such that the only patient group with significant decrease in confirmed disability progression on drug treatment were those diagnosed within 10 years. $^{30}$

\section{TIMING OF DISEASE MANAGEMENT: THE CASE FOR CONTINUED TREATMENT OF PROGRESSIVE DISEASE}

One inference of the 'treat early' concept is that, beyond a certain point of disability, usually expressed as around stage 3 or 4 on the EDSS, the disease can no longer be modified ${ }^{31}$ and DMT is therefore without merit. ${ }^{32}$ That inference has more recently been challenged following review of past trial evidence $e^{334}$ and new data, ${ }^{35} 36$ indicating that even people at a more advanced stage of MS may benefit from DMT.

The difference in responsiveness to DMT between upper limb (and cognitive problems) and lower limb (and, for example, bladder) dysfunction suggests a degree of length dependency of nerve damage. ${ }^{33} 3738$ Evidence suggests nerve fibre tracts to the lower spine are more likely to be damaged in more places than shorter nerve fibre tracts. ${ }^{3739}$ Moreover, more than 50\% of corticospinal tract fibres have already terminated once they approach the neck portion of the spinal cord, providing a naturally higher redundancy of tracts supplying the arms and hands, and other important for functions such as swallowing and speech. ${ }^{38} 4041$

We are now seeing increasing evidence that disease modification is possible at later stages of disease, even after walking function has been lost. ${ }^{33} 344243$ Patients value upper limb function and are keen to be included in studies after the loss of walking ability - a recent survey showed $95 \%$ of patients disagree with the idea that wheelchair users should be excluded from MS studies. $^{44}$

A study published last year showed that the anti-CD20 monoclonal antibody ocrelizumab can slow deterioration in people with primary progressive MS, with a $25 \%$ reduction in EDSS-measured disability progression at 12 and 24 weeks. ${ }^{45}$ Looking at upper limb function, the study reported a $44 \%$ difference in upper limb function between treated and non-treated patients, in line with the length dependency hypothesis. ${ }^{46}$

Ocrelizumab is the first drug to have been licensed for primary progressive MS. A phase III trial of fingolimod (INFORMS) failed to show an overall impact of the drug on disability in progressive MS. ${ }^{47}$ However, case studies from the trial suggest that some patients do indeed benefit from the treatment. One patient enrolled in the INFORMS trial had a catastrophic deterioration 4 months after discontinuing fingolimod as a result of the trial termination, which was due to the negative outcome of the cohort on the primary endpoint (EDSS). She experienced a step change in disability level from EDSS 6.5 to 8 and hand function in particular. Subsequent treatment with off-label cladribine helped her regain some of the lost function. ${ }^{48}$

Evidence from MRI and other studies clearly shows that the concept of progressive $\mathrm{MS}^{49}$ as a 'non-inflammatory stage' of MS is wrong. ${ }^{50}$ Earlier pathology studies demonstrated significant association between inflammation and axonal damage, regardless of whether the patient had progressive or relapsing MS. ${ }^{51-53}$

While anti-inflammatory disease-modifying treatment should be started as early as possible, it should not necessarily be given up when patients develop progressive MS. To demonstrate benefit, trials will need to include outcomes that are sensitive to functions that can be protected or recovered at an advanced stage of the disease, including upper limb function, dexterity, swallowing and speech. ${ }^{54}$ High-quality surrogate indices, such as the impact of new compounds on MRI indices of brain or spinal cord volume, are useful in phase II trials to estimate likely clinical benefit. ${ }^{55-57}$

It is important to bear in mind that clinical and surrogate indices should reflect changes that are meaningful for people with MS. The concept of 'treat early and never stop' should be mindful of the adverse effects associated with DMTs-predominantly lowered immune function and increased susceptibility to infection and neoplasms. ${ }^{1}$

For a fully informed treatment choice, people with MS need time for comprehensive education about all aspects of their DMT management. Early treatment with a highly effective DMT may be beneficial in terms of disease control but at the trade-off of increased risk of adverse effects. For example, alemtuzumab leads to no evidence of disease activity over years in more than $60 \%$ of patients and a nearly normalised brain atrophy rate in many, ${ }^{58}$ but the risk of secondary autoimmunity can reach nearly $50 \% .^{59}$

The long-term value of such an intervention, compared with an escalation strategy, remains to be confirmed. The number of effective compounds has increased significantly over recent years, and high efficacy is not now always synonymous with high risk. ${ }^{60-62}$ Patients and physicians should keep an open mind, be prepared to monitor efficacy and adverse effects, and switch DMT as required.

Early detection and diagnosis may allow for suppression of inflammation to a degree that could prevent or stop the development of neurodegeneration. For example, data from the alemtuzumab programme indicate that such high efficacy with long-term remission can be achieved in some patients. ${ }^{5963}$

\section{AGEING WITH MS: TIME TO INTERVENE IN VASCULAR DISEASE PREVENTION}

MS is a chronic disease, in the majority of cases, initially characterised by acute bouts of inflammation that translate into transient neurological dysfunction. At some point—often around age 40-50- the clinical phenotype may transition to a progressive phase, ${ }^{64-67}$ during which further mechanisms, over and above focal inflammatory demyelination, contribute to disease evolution. ${ }^{6869}$ These include mitochondrial dysfunction, ${ }^{68}$ hypoxia, ${ }^{70}$ 
iron accumulation ${ }^{68}$ and fibrogen deposition, ${ }^{71}$ and contribute to amplify neurodegeneration, ${ }^{68} 72$ particularly in late-stage disease or older patients, where inflammation is less prominent $^{5373}$ and neuronal loss seems to be relatively independent from demyelination. ${ }^{10}$

Older age seems to influence the clinical phenotype, patients with progression from disease onset being typically older than those with a relapsing remitting onset. Age influences the onset and transition into clinical progressive MS and the pathological hallmarks and mechanisms which feature progressive disease, despite the initial clinical phenotype. ${ }^{74}$

Vascular disease is also an age-related phenomenon, with an accumulation of atheroma in blood vessels from an early age, which can lead later in life to heart disease (around the age of 50s and 60s) and brain damage (after the age of 60). ${ }^{75}$ Vascular risk factors such as hypertension, diabetes and dyslipidaemia also contribute to the accumulation of vessel atheroma and have been linked to changes in the brain, including brain volume loss, white matter lesions and small haemorrhages visible on the MRI scans of people with vascular risk factors but no MS. In turn, these changes correlate with cognitive dysfunction and walking impairment. ${ }^{7677}$

A key and unresolved question is whether people with MS have an increased risk of vascular disease such as stroke, compared with people without MS. ${ }^{78-81}$ Epidemiological data suggest that cardiovascular disease is an important cause of death in MS, ${ }^{82}$ and that people with MS have a small increase in risk of stroke. ${ }^{80}$ However, this finding should be treated with caution, as it could be due to surveillance bias or the impact of immobilisation that features in late-stage MS. ${ }^{78}$ Morphological changes in brain blood vessels, such as vessel wall thickening, have been described in people with MS. ${ }^{83} 84$ As in other inflammatory disorders such as rheumatic diseases, ${ }^{85}$ cerebral vessels exposed to MS chronic inflammation could be prone to atheroma and atherosclerosis. This hypothesis is to be investigated.

Even if patients with MS do not have a greater risk of vascular disease than the general population, $17 \%$ of all patients with MS have hypertension and $8 \%$ have hyperlipidaemia at the time of diagnosis, ${ }^{86}$ with older patients with MS having a higher prevalence of these vascular risk factors. ${ }^{4}$

Vascular risk factors and disease are associated with worse outcomes in people with MS. It is well known that smoking reduces time to secondary progression, but perhaps less well known that the presence of any vascular risk factor is linked to reduced time to walking disability. ${ }^{8788}$ The exact mechanisms underlying the effect of vascular risk factors in disability are unclear, but it is possible that blood vessels already exposed to chronic inflammation are put under additional pressure through vascular risk factors. ${ }^{89}$

It is not difficult to see why this might be. Cerebral blood vessels provide oxygen and nutrients to nerve cells, and are key intermediaries between nerve cells and the immune system. Damaged blood vessels contribute to nerve hypoperfusion and hypoxia, and there is evidence of brain hypoperfusion in MS. Maps of cerebral blood flow show that areas of low blood perfusion colocalise with both T1 and T2 MS lesions, ${ }^{90}$ and MS lesions tend to accumulate in 'watershed' areas (areas between two vascular territories, where there is hypoperfusion). ${ }^{91}$

MS and small vessel cerebrovascular disease may be difficult to distinguish. ${ }^{92} 93$ More specific markers are required to enable clinicians to distinguish between MS progression that might be treated by DMTs and cerebral damage that is a result of cerebrovascular disease. While clinical studies of vascular risk factors in MS are hard to envisage, large-scale epidemiological studies, drawing on big data from patient databases, may provide some answers. This might help to untangle the ways in which each vascular risk factor has an impact on the progression of MS.

Although the association between vascular disease and MS is not fully understood, it is possible that vascular risk factors ${ }^{9495}$ or vascular pathology can cause additional damage to the brains of people with MS, over and above that caused by MS alone. ${ }^{70997}$ Although this needs further confirmation, information about patients' vascular status should be incorporated into clinical trials. MS is a heterogeneous disease, and at the individual level the time to reach the secondary progressive phase is variable. The role of age-related vascular disease on MS progression onset and phenotypic presentation has still to be investigated. If time matters in protecting the brain from inflammation-related damage in relapsing remitting MS, it also matters in protecting the brain from additional damage from vascular disease.

We know that patients who stop smoking sooner have better outcomes. ${ }^{98}$ It is time to take other vascular risk factors seriously. Clinicians should talk to patients about vascular risk and encourage them to take preventive action in the form of smoking cessation, diet and exercise. Vascular risk factors or morbidities such as hypertension should be assessed and treated, before they begin to add to the burden of brain damage. Proper, timely interventions in patients' vascular health may help buy additional time to treat MS. Integrated care requires consideration of the body outside of the nervous system, as well as the nervous system and brain.

\section{COSTS AND BURDENS OF MS}

Part of the struggle to ensure everyone who needs appropriate treatment for MS can access it stems from concerns around costs. Uncovering the true benefits of MS treatment could help the MS community to make the case for funding of treatment.

Because MS is a disease in which disability accrues slowly, yet studies of treatment are often of only 2-3 years' duration, it can be challenging to show the full extent of the benefits. Health economists look for data that demonstrate quality of life gains for the individual affected, yet this may not capture the full extent of the economic benefits of treatment-not only for the health service and the person being treated, but for their carers as well.

MS is an expensive disease, and the costs rise sharply in line with increased disability and plummeting quality of life. Two new studies have gathered more data about the burdens and costs of MS in Europe. The aim is to demonstrate evidence of the impact of an effect of treatment on disease progression that will prevent or delay patients reaching a disease state with higher costs and lower quality of life.

The first of these studies is the largest study ever performed of MS disease burden and treatment. ${ }^{99}$ The observational, cross-sectional study included data from 16808 patients from 16 countries across Europe. Patients were contacted by national MS societies and provided data collected by questionnaires, either online or in printed form. The study collected information on patient characteristics, disease type, use of resources and loss of resource (including work capacity) over the previous 3 months' period. The EDSS was used to stratify patients by disease level.

Results were highly heterogeneous between countries, including sample size, average age and disability level. The results also reflected differences in healthcare systems and informal care traditions in different countries. However, the findings confirmed the relationship between costs and disability, 
a finding that costs increase on average fivefold between mild and severe MS.

One clear difference was in the proportion of patients using DMTs. Spain, France and Portugal had the highest proportion of patients taking these medications. These results may have reflected the average level of disability and disease type in the cohort of each country. The UK cohort, for example, had a higher proportion of patients with progressive disease, which may explain the relatively low proportion using DMTs. Overall, the study found, as might be expected, that DMTs are more frequently used at lower EDSS scores, and very little used in people with higher EDSS scores. Fatigue and cognitive difficulties have a major effect on patients' productivity. The study results suggest that renewed focus on fatigue and cognitive function is critical. They are not incidental symptoms, but a fundamental manifestation of MS which should be actively managed.

The study found that many patients of working age were not working, and that this reached $50 \%$ of the cohort at EDSS score of 3.5. The implication is that MS affects employment status before physical disability sets in. Some $95 \%$ of patients complained of fatigue and cognitive difficulties. Given the difficulty of objectively assessing one's own cognitive function, this may be an underestimate.

The study findings on healthcare resource use provide an insight into different healthcare models. The proportion of patients who reported having seen a neurologist in the past 3 months varied considerably, from $81 \%$ in Germany to $25 \%$ in the UK. This correlated inversely with use of specialist nurseswhere patients frequently saw neurologists, they were less likely to have seen an MS nurse or a physiotherapist.

The study showed wide variation in the models of care. While data from a 'snapshot' cross-sectional study are difficult to evaluate, some countries have done work to evaluate the cost-effectiveness of different models of care. The results may help the MS community to develop an optimum model of care, which might cover access to DMTs, early treatment, high-quality services and the optimal balance between different healthcare professionals. The heterogeneity of findings suggests that healthcare consumption is currently more influenced by systems and tradition than by the disease itself.

Some countries had a very high percentage of informal care, possibly relating to the traditional care models in that country. Others had less use of informal care, which might relate to more developed formal care services or more access to formal care services. For most countries, use of informal care increased with increasing disability scores. In some countries, informal carers were providing 150 hours a month of care to patients-the equivalent of full-time employment. ${ }^{99}$

Further insight into the experience of patients and carers came from the International Multiple Sclerosis Study (IMPrESS), which included an online survey of 1152 people with MS and 265 carers from 19 countries. ${ }^{100}$

Most patients had relapsing MS, although some were unsure, reflecting the confusion around classification of MS. Most patients were treated with DMTs (around 80\% of those with relapsing MS and, surprisingly, almost all those with primary progressive MS). However, only a fraction of these people were taking oral DMTs. Patients who had received prompt treatment-within 12 months of first symptoms plus confirmatory MRI evidence-were more likely to be taking oral DMTs and reported fewer hospital admissions, compared with those whose treatment was delayed beyond 12 months.

The study revealed a 'care gap' between the amount of care people received and the amount they believed they needed.
Questions about quality of life and disability score showed that the EuroQol Five Dimensions questionnaire may not necessarily capture what matters most to patients-notably fatigue, weakness, balance and dizziness. Patients say these things are important to them, yet they are not captured by generalised quality of life questions. Patients tend to rate themselves relatively highly on quality of life, even when their disability score suggests they are not doing so well.

The study found that patients rate access to information very highly and tend to look online for information, primarily from MS-specific organisations or charities. Patients felt they needed good-quality information to participate in shared decision-making. While they valued the opinion of the clinician, they also wanted the opportunity to discuss options with them, and $67 \%$ said they wanted to be active in the decision-making process and management of their care.

The figures about informal care backed up the findings of the bigger study, showing a huge impact on carers' economic activity, with an annual figure of $€ 31653$ loss of productivity. Despite this, carers tended not to rate their caring duties as burdensome.

Taken together, these studies demonstrate that the greatest costs of MS are not the drugs to treat the disease, but the cost of informal care and loss of productivity, both of patients and their informal carers. Bringing new evidence about these costs into health technology assessments would be a step forward in recognising the contributions of informal care and the costs incurred.

\section{EARLY EVIDENCE FOR ECONOMIC ANALYSIS}

Despite the advances made in DMT for patients with relapsing MS over the past 25 years, patients who develop secondary progressive MS which make up to more than half of the MS population do not currently have access to a therapy licensed for their treatment. This would target progressive MS besides Primary MS. ${ }^{101}$

This is in part a reflection of our limited understanding of the mechanisms underpinning progression, in addition to the complex hurdles that therapies must overcome to gain a licence for an indication and to be judged both cost-effective and affordable by those meeting the costs of therapy.

Based on the indication for which the licence is grantedwhich with MS is often restricted by disease severity or stageindividual countries will determine whether to reimburse the drug through their healthcare system, using health technology assessment. This process, which usually takes at least 12 months, will consider cost-effectiveness and value for money and will look for added therapeutic value.

The two further decision-makers, after the regulatory authorities and the payment authorities have had their say, are the prescribers-who consider the likely performance of the drug compared with other therapies for the individual patient-and potentially the patient, who may have to decide whether he or she is willing or able to pay for the treatment (if they pay directly for medical care) and whether to adhere to treatment. ${ }^{102}$

How can this process be speeded up so that effective therapies can get to the patients who benefit from them more quickly?

Phase II trials can be extended to look at disability endpoints and provide longer term data, which may be helpful for health technology assessment. Phase III trials tend to include disability endpoints and the sustained effect of therapies on disability. However, while these trials can look at impairments-what level of disability scores people have and how these change over time-they are less good at considering how impairments affect the patient's activities and role in society. This is complicated, 
because two patients with similar impairments may feel they have different levels of disability, perhaps based on external factors such as their social support and expectations. This makes it very difficult to truly measure the impact of disability. ${ }^{103}$

Tools that assess the effects of limitations on activities and participation in society do exist, but are not specific enough to be sure that the limitation is caused by MS. A combination of MS-specific disability measures and these wider tools might give us a better picture, but this would be excessively cumbersome for use in routine assessments. Most endpoints currently measured look at clinical signs, not functioning. Global functional tools are variable and have a bias towards diagnosis of depression. There is a need to develop better tools to measure disability and its effect on patients' functioning and societal role, if we are to provide good evidence of the true burden of MS on society, and the related cost-benefit of therapies.

Meantime, we need to find a way to get therapies that are licensed for one indication and now off-patent (such as statins) but may have useful activity for MS, into the health technology appraisal system. At present, there is no incentive for a manufacturer to fund an expensive clinical trial of statins for treatment of MS, and most health technology assessment systems will only assess therapies licensed for the indication being proposed. ${ }^{104}$

\section{CONCLUSION}

New insights about the timing and duration of MS therapies, and about the importance of comorbidities, present us with great opportunities to make significant improvements to the lives of people with MS.

While the research we outline highlights a significant level of unmet need in a relatively young and economically active population, this information can be used to press for more widespread adoption of the principles of early effective treatment and long-term follow-up to keep disease activity in check. This adoption must come now not just from clinicians and patients, but also from drug regulators and payers (insurers and tax-funded healthcare).

More widespread adoption of these principles could help us to build on the successes of the therapeutic advances we have seen over the past 25 years, ensuring that everyone who can benefit from treatment does so and that no patients are left behind. We already know that 'time matters' when treating MS. Now it is time to take that message to those planning services, regulating healthcare technologies and setting the healthcare agenda.

\section{Acknowledgements The authors thank Anna Sayburn for the contribution towards taking notes during the presentations and round table discussions and drafting the original manuscript.}

Funding This study was funded by F Hoffmann-La Roche.

Competing interests AT: received honoraria/support for travel for consultancy from Eisai, Hoffman La Roche, and Excemed. He received support for travel from the International Progressive MS Alliance, as chair of their Scientific Steering Committee and the National MS Society (USA) as member of their Research Programs Advisory Committee. He receives an honorarium from SAGE Publishers as Editor-in-Chief of Multiple Sclerosis Journal, and a free subscription from Elsevier as a board member for the Lancet Neurology. JP: support for scientific meetings and honorariums for advisory work from Merck Serono, ABIDE, Biogen Idec, Novartis, Alexion, Medlmmune, Teva, Chugai Pharma and Bayer Schering, and unrestricted grants from Merck Serono, Novartis, Biogen Idec and Bayer Schering; funded to run a highly specialised service for neuromyelitis optica and congenital myasthenia; grants from the MS Society; GMSI, NIHR and Guthy-Jackson Foundation for research studies. JJC: speaker's honoraria and consulting fees from Biogen, Novartis, Merck, Bayer, Teva, Genzyme and Roche; research grant from Biogen; President-Elect, Portuguese MS Study Group; scientific council member, MS Patient's Association ('Todos com a Esclerose Múltipla'). KS: speaking honoraria from, and/or served in an advisory role for, Biogen, Merck, Novartis, Roche and Teva; supported for attendance of meetings by Genzyme, Merck and Novartis; PI of trials sponsored by Novartis, Roche, Teva and Medday; involved in trials sponsored by Biogen, Genzyme, BIAL, Cytokinetics and Canbex; research grant support from Novartis and Biogen. RG: support for scientific meetings and courses and honorariums for advisory work from Biogen Idec, Novartis, Bayer Schering, Merck Serono and Teva; this does not relate to the theme of presentation on the interaction of vascular comorbidities in multiple sclerosis. DASC: attended a company-sponsored event (Sanofi-Genzyme) for which he will be reimbursed modest travel costs and paid an honorarium; acts as a paid scientific advisor to the Lundbeck Foundation (Denmark).

\section{Patient consent Not required.}

Provenance and peer review Not commissioned; externally peer reviewed.

Open access This is an open access article distributed in accordance with the Creative Commons Attribution Non Commercial (CC BY-NC 4.0) license, which permits others to distribute, remix, adapt, build upon this work non-commercially, and license their derivative works on different terms, provided the original work is properly cited and the use is non-commercial. See: http://creativecommons.org/ licenses/by-nc/4.0/

(c) Article author(s) (or their employer(s) unless otherwise stated in the text of the article) 2018. All rights reserved. No commercial use is permitted unless otherwise expressly granted.

\section{REFERENCES}

1 Wingerchuk DM, Weinshenker BG. Disease modifying therapies for relapsing multiple sclerosis. BMJ 2016;354:i3518.

2 Solaro C, Ponzio M, Moran E, et al. The changing face of multiple sclerosis: Prevalence and incidence in an aging population. Mult Scler 2015;21:1244-50.

3 Lunde HMB, Assmus J, Myhr KM, et al. Survival and cause of death in multiple sclerosis: a 60-year longitudinal population study. J Neurol Neurosurg Psychiatry 2017;88:621-5.

4 Marrie RA. Comorbidity in multiple sclerosis: implications for patient care. Nat Rev Neurol 2017:13:375-82.

5 Kutzelnigg A, Lucchinetti CF, Stadelmann C, et al. Cortical demyelination and diffuse white matter injury in multiple sclerosis. Brain 2005;128(Pt 11):2705-12.

6 Nikić I, Merkler D, Sorbara C, et al. A reversible form of axon damage in experimental autoimmune encephalomyelitis and multiple sclerosis. Nat Med 2011;17:495-9.

7 Popescu BF, Pirko I, Lucchinetti CF. Pathology of multiple sclerosis: where do we stand? Continuum 2013;19:901-21.

8 De Stefano N, Stromillo ML, Giorgio A, et al. Establishing pathological cutoffs of brain atrophy rates in multiple sclerosis. J Neurol Neurosurg Psychiatry 2016;87:93-9.

9 De Stefano N, Giorgio A, Battaglini M, et al. Assessing brain atrophy rates in a large population of untreated multiple sclerosis subtypes. Neurology 2010;74:1868-76.

10 Carassiti D, Altmann DR, Petrova N, et al. Neuronal loss, demyelination and volume change in the multiple sclerosis neocortex. Neuropathol Appl Neurobiol 2017.

11 Kolasinski J, Stagg CJ, Chance SA, et al. A combined post-mortem magnetic resonance imaging and quantitative histological study of multiple sclerosis pathology. Brain 2012;135:2938-51.

12 Popescu V, Klaver R, Voorn P, et al. What drives MRI-measured cortical atrophy in multiple sclerosis? Mult Scler 2015;21:1280-90.

13 Klaver R, De Vries HE, Schenk GJ, et al. Grey matter damage in multiple sclerosis: a pathology perspective. Prion 2013 7:66-75.

14 Popescu V, Klaver R, Versteeg A, et al. Postmortem validation of MRI cortical volume measurements in MS. Hum Brain Mapp 2016:37:2223-33.

15 Charles P, Reynolds R, Seilhean D, et al. Re-expression of PSA-NCAM by demyelinated axons: an inhibitor of remyelination in multiple sclerosis? Brain 2002;125(Pt 9):1972-9.

16 Kuhlmann T, Miron V, Cui Q, et al. Differentiation block of oligodendroglial progenitor cells as a cause for remyelination failure in chronic multiple sclerosis. Brain 2008;131(Pt 7):1749-58.

17 Goldschmidt T, Antel J, König FB, et al. Remyelination capacity of the MS brain decreases with disease chronicity. Neurology 2009;72:1914-21.

18 Cadavid D, Edwards KR, Hupperts R, et al. Efficacy analysis of opicinumab in relapsing multiple sclerosis: the Phase $2 b$ SYNERGY trial: ECTRIMS Online Library, 2016.

19 Giovannoni G, Butzkueven H, Dhib-Jalbut S, et al. Brain health: time matters in multiple sclerosis. UK: Oxford PharmaGenesis, 2015.

20 Strober L, Chiaravalloti N, Moore N, et al. Unemployment in multiple sclerosis (MS): utility of the MS Functional Composite and cognitive testing. Mult Scler 2014;20:112-5

21 Achiron A, Polliack M, Rao SM, et al. Cognitive patterns and progression in multiple sclerosis: construction and validation of percentile curves. J Neurol Neurosurg Psychiatry 2005;76:744-9.

22 Amato MP, Hakiki B, Goretti B, et al. Association of MRI metrics and cognitive impairment in radiologically isolated syndromes. Neurology 2012;78:309-14.

23 Bonnet MC, Allard M, Dilharreguy B, et al. Cognitive compensation failure in multiple sclerosis. Neurology 2010;75:1241-8. 
24 Schoonheim MM, Meijer KA, Geurts JJ. Network collapse and cognitive impairment in multiple sclerosis. Front Neurol 2015:6:82.

25 Rocca MA, Riccitelli GC, Meani A, Falini A, Filippi M, et al. Cognitive reserve, cognition, and regional brain damage in MS: A 2 -year longitudinal study. Mult Scler 2018;1:1352458517750767

26 Sinay V, Perez Akly M, Zanga G, et al. School performance as a marker of cognitive decline prior to diagnosis of multiple sclerosis. Mult Scler 2015;21:945-52.

27 Goodin DS, Reder AT, Ebers GC, et al. Survival in MS: a randomized cohort study 21 years after the start of the pivotal IFN $\beta$-1b trial. Neurology 2012;78:1315-22.

28 O'Connor P, Goodman A, Kappos L, et al. Long-term safety and effectiveness of natalizumab redosing and treatment in the STRATA MS Study. Neurology 2014;83:78-86.

29 Tremlett $H$, Zhao Y, Rieckmann P, et al. New perspectives in the natural history of multiple sclerosis. Neurology 2010;74:2004-15.

30 Kappos L, Bar-Or A, Cree B, et al. Efficacy and safety of siponimod in secondary progressive multiple sclerosis - Results of the placebo controlled, double-blind, Phase III EXPAND study: ECTRIMS Online Library, 2016.

31 Leray E, Yaouanq J, Le Page E, et al. Evidence for a two-stage disability progression in multiple sclerosis. Brain 2010:133:1900-13.

32 Coles AJ, Cox A, Le Page E, et al. The window of therapeutic opportunity in multiple sclerosis: evidence from monoclonal antibody therapy. J Neurol 2006;253:98-108

33 Goodkin DE, Rudick RA, VanderBrug Medendorp S, et al. Low-dose (7.5 mg) oral methotrexate reduces the rate of progression in chronic progressive multiple sclerosis. Ann Neurol 1995;37:30-40.

34 Tur $C$, Montalban $X$, Tintoré $M$, et al. Interferon $\beta$ - $1 \mathrm{~b}$ for the treatment of primary progressive multiple sclerosis: five-year clinical trial follow-up. Arch Neurol 2011:68:1421-7.

35 Giovannoni G, Steiner D, Sellebjerg F, et al. Sustained disability improvement in patients with secondary progressive multiple sclerosis (SPMS) assessed by a multicomponent endpoint: a post hoc analysis from the ASCEND study. Multiple Sclerosis Journal 2016;22:671-2.

36 Montalban X, Hauser SL, Kappos L, et al. Ocrelizumab versus Placebo in Primary Progressive Multiple Sclerosis. N Engl J Med 2017;376:209-20.

37 Giovannoni G, Cutter G, Sormani MP, et al. Is multiple sclerosis a length-dependent central axonopathy? The case for therapeutic lag and the asynchronous progressive MS hypotheses. Mult Scler Relat Disord 2017;12:70-8.

38 Patestas MA, Gartner LP. A textbook of neuroanatomy. US: John Wiley \& Sons, 2016

39 Petrova N, Carassiti D, Altmann DR, et al. Axonal loss in the multiple sclerosis spinal cord revisited. Brain Pathol 2017.

40 Kurtzke JF. On the origin of EDSS. Mult Scler Relat Disord 2015;4:95-103.

41 Schieber MH. Constraints on somatotopic organization in the primary motor cortex. J Neurophysiol 2001;86:2125-43.

42 Cohen JA, Cutter GR, Fischer JS, et al. Benefit of interferon beta-1a on MSFC progression in secondary progressive MS. Neurology 2002;59:679-87.

43 Giovannoni G, Arnold DL, Bar-Or A, et al. An exploratory analysis of 12-and 24-week composite confirmed disability progression in patients with primary progressive multiple sclerosis in the ORATORIO trial. 2016 http://www.forskningsdatabasen.dk/ en/catalog/2347738993

44 Thomson A, Giovannoni G, Marta $\mathrm{M}$, et al. Importance of upper limb function in advanced MS: ECTRIMS, 2016.

45 Montalban X, Hauser SL, Kappos L, et al. Ocrelizumab versus placebo in primary progressive multiple sclerosis. N Engl J Med 2017;376:209-20.

46 Giovanni G, Arnold DL, Bar-Or A, et al. An exploratory analysis of 12- and 24-week composite confirmed disability progression in patients with primary progressive multiple sclerosis in the ORATORIO trial. 2016 https://onlinelibrary.ectrims-congress. eu/ectrims/2016/32nd/146586/gavin.giovannoni.an.exploratory.analysis.of.12-.and. 24-week.composite.html?f=m3

47 Lublin F, Miller DH, Freedman MS, et al. Oral fingolimod in primary progressive multiple sclerosis (INFORMS): a phase 3, randomised, double-blind, placebocontrolled trial. Lancet 2016:387:1075-84.

48 Alvarez-Gonzalez C, Adams A, Mathews J, et al. Cladribine to treat disease exacerbation after fingolimod discontinuation in progressive multiple sclerosis. Ann Clin Transl Neurol 2017:4:506-11.

49 Leray E, Yaouanq J, Le Page E, et al. Evidence for a two-stage disability progression in multiple sclerosis. Brain 2010;133(Pt 7):1900-13.

50 Steinman L, Zamvil SS. Beginning of the end of two-stage theory purporting that inflammation then degeneration explains pathogenesis of progressive multiple sclerosis. Curr Opin Neurol 2016;29:340-4.

51 Magliozzi R, Howell O, Vora A, et al. Meningeal B-cell follicles in secondary progressive multiple sclerosis associate with early onset of disease and severe cortical pathology. Brain 2007;130:1089-104.

52 Howell OW, Reeves CA, Nicholas R, et al. Meningeal inflammation is widespread and linked to cortical pathology in multiple sclerosis. Brain 2011;134:2755-71.

53 Frischer JM, Bramow S, Dal-Bianco A, et al. The relation between inflammation and neurodegeneration in multiple sclerosis brains. Brain 2009;132(Pt 5):1175-89.

54 Dubuisson N, Baker D, Thomson A, et al. Disease modification in advanced MS: Focus on upper limb function. Mult Scler 2017;23:1956-7.
55 Kapoor R, Furby J, Hayton T, et al. Lamotrigine for neuroprotection in secondary progressive multiple sclerosis: a randomised, double-blind, placebo-controlled, parallel-group trial. Lancet Neurol 2010;9:681-8.

56 Chataway J. MS-STAT investigators. Simvastatin in patients with progressive multiple sclerosis--Authors' reply. Lancet 2014;384:952-3.

57 Rice CM, Marks DI, Ben-Shlomo Y, et al. Assessment of bone marrow-derived Cellular Therapy in progressive Multiple Sclerosis (ACTiMuS): study protocol for a randomised controlled trial. Trials 2015:16:463.

58 Giovannoni G, Turner B, Gnanapavan S, et al. Is it time to target no evident disease activity (NEDA) in multiple sclerosis? Mult Scler Relat Disord 2015;4:329-33.

59 Tuohy O, Costelloe L, Hill-Cawthorne G, et al. Alemtuzumab treatment of multiple sclerosis: long-term safety and efficacy. J Neurol Neurosurg Psychiatry 2015:86:208-15.

60 Hauser SL, Bar-Or A, Comi G, et al. Ocrelizumab versus Interferon Beta-1a in Relapsing Multiple Sclerosis. N Engl J Med 2017:376:221-34.

61 Pakpoor J, Disanto G, Altmann DR, et al. No evidence for higher risk of cancer in patients with multiple sclerosis taking cladribine. Neurol Neuroimmunol Neuroinflamm 2015;2:e158.

62 Wiendl H. Cladribine - an old newcomer for pulsed immune reconstitution in MS. Nat Rev Neurol 2017;13:573-4.

63 Coles AJ, Cohen JA, Fox EJ, et al. Alemtuzumab CARE-MS II 5-year follow-up: Efficacy and safety findings. Neurology 2017;89:1117-26.

64 Tutuncu M, Tang J, Zeid NA, et al. Onset of progressive phase is an age-dependent clinical milestone in multiple sclerosis. Mult Scler 2013;19:188-98.

65 Confavreux C, Vukusic S. Age at disability milestones in multiple sclerosis. Brain 2006:129:595-605.

66 Cossburn M, Ingram G, Hirst C, et al. Age at onset as a determinant of presenting phenotype and initial relapse recovery in multiple sclerosis. Mult Scler 2012;18:45-54

67 Scalfari A, Neuhaus A, Daumer $M$, et al. Onset of secondary progressive phase and long-term evolution of multiple sclerosis. J Neurol Neurosurg Psychiatry 2014:85:67-75

68 Mahad DH, Trapp BD, Lassmann H. Pathological mechanisms in progressive multiple sclerosis. Lancet Neurol 2015 14:183-93.

69 Confavreux C, Vukusic S. Age at disability milestones in multiple sclerosis. Brain 2006;129(Pt 3):595-605.

70 Martinez Sosa S, Smith KJ. Understanding a role for hypoxia in lesion formation and location in the deep and periventricular white matter in small vessel disease and multiple sclerosis. Clin Sci 2017:131:2503-24

71 Yates RL, Esiri MM, Palace J, et al. Fibrin(ogen) and neurodegeneration in the progressive multiple sclerosis cortex. Ann Neurol 2017;82:259-70.

72 Correale J, Gaitán MI, Ysrraelit MC, et al. Progressive multiple sclerosis: from pathogenic mechanisms to treatment. Brain 2016:56:aww258.

73 Frischer JM, Weigand SD, Guo Y, et al. Clinical and pathological insights into the dynamic nature of the white matter multiple sclerosis plaque. Ann Neurol 2015:78:710-21.

74 Zeydan B, Kantarci OH. Progressive forms of multiple sclerosis. Neurol Clin 2018;36:163-71.

75 Qiu C, Fratiglioni L. A major role for cardiovascular burden in age-related cognitive decline. Nat Rev Cardiol 2015 12:267-77.

76 Staals J, Makin SD, Doubal FN, et al. Stroke subtype, vascular risk factors, and total MRI brain small-vessel disease burden. Neurology 2014;83:1228-34.

77 Rostrup E, Gouw AA, Vrenken H, et al. The spatial distribution of age-related white matter changes as a function of vascular risk factors-results from the LADIS study. Neuroimage 2012:60:1597-607.

78 Roshanisefat $\mathrm{H}$, Bahmanyar S, Hillert J, et al. Multiple sclerosis clinical course and cardiovascular disease risk - Swedish cohort study. Eur J Neurol 2014;21:1353-e88.

79 Christiansen CF. Risk of vascular disease in patients with multiple sclerosis: a review. Neurol Res 2012;34:746-53

80 Thormann A, Magyari M, Koch-Henriksen N, et al. Vascular comorbidities in multiple sclerosis: a nationwide study from Denmark. J Neurol 2016;263:2484-93.

81 Marrie RA, Reider N, Cohen J, et al. A systematic review of the incidence and prevalence of cardiac, cerebrovascular, and peripheral vascular disease in multiple sclerosis. Mult Scler 2015;21:318-31.

82 Goodin DS, Corwin M, Kaufman D, et al. Causes of death among commercially insured multiple sclerosis patients in the United States. PLoS One 2014;9:e105207.

83 Adams CW. Perivascular iron deposition and other vascular damage in multiple sclerosis. J Neurol Neurosurg Psychiatry 1988;51:260-5.

84 Geraldes R, Esiri MM, DeLuca GC, et al. Age-related small vessel disease: a potentia contributor to neurodegeneration in multiple sclerosis. Brain Pathol 2017;27.

85 Castañeda S, Nurmohamed MT, González-Gay MA. Cardiovascular disease in inflammatory rheumatic diseases. Best Pract Res Clin Rheumatol 2016;30:851-69.

86 Marrie RA, Patten SB, Tremlett H, et al. Sex differences in comorbidity at diagnosis of multiple sclerosis: A population-based study. Neurology 2016;86:1279-86.

87 Manouchehrinia A, Tench CR, Maxted J, et al. Tobacco smoking and disability progression in multiple sclerosis: United Kingdom cohort study. Brain 2013;136(Pt 7):2298-304 
88 Marrie RA, Rudick R, Horwitz R, et al. Vascular comorbidity is associated with more rapid disability progression in multiple sclerosis. Neurology 2010;74:1041-7.

89 Gisterå A, Hansson GK. The immunology of atherosclerosis. Nat Rev Nephrol 2017; 13:368-80.

90 Narayana PA, Zhou Y, Hasan KM, et al. Hypoperfusion and T1-hypointense lesions in white matter in multiple sclerosis. Mult Scler 2014;20:365-73.

91 Haider L, Zrzavy T, Hametner S, et al. The topograpy of demyelination and neurodegeneration in the multiple sclerosis brain. Brain 2016;139(Pt 3):807-15.

92 Schmidt R, Enzinger C, Ropele S, et al. Subcortical vascular cognitive impairment: similarities and differences with multiple sclerosis. J Neuro/ Sci 2006;245:3-7.

93 Renard D, Castelnovo G, Bousquet P-J, et al. Brain MRI findings in long-standing and disabling multiple sclerosis in 84 patients. Clin Neurol Neurosurg 2010 112:286-90.

94 Pichler A, Khalil M, Langkammer C, et al. The impact of vascular risk factors on brain volume and lesion load in patients with early multiple sclerosis. Mult Scler 2017:87:135245851773614.

95 Kowalec K, McKay KA, Patten SB, et al. Comorbidity increases the risk of relapse in multiple sclerosis: A prospective study. Neurology 2017:89:2455-61.

96 Geraldes R, Esiri MM, DeLuca GC, et al. Age-related small vessel disease: a potential contributor to neurodegeneration in multiple sclerosis. Brain Pathol 2017;27:707-22.
97 Spencer JI, Bell JS, DeLuca GC. Vascular pathology in multiple sclerosis: reframing pathogenesis around the blood-brain barrier. J Neurol Neurosurg Psychiatry 2018;89:42-52.

98 Tanasescu R, Constantinescu CS, Tench CR, et al. Smoking cessation and the reduction of disability progression in Multiple Sclerosis: a cohort study. Nicotine Tob Res 2017.

99 Kobelt G, Thompson A, Berg J, et al. New insights into the burden and costs of multiple sclerosis in Europe. Mult Scler 2017;23:1123-36.

100 Tinelli M, Kanavos P. Using IMPrESS (International MultiPIE Sclerosis Study) to guide policy change in multiple sclerosis. Multiple Sclerosis Journal. In Press.

101 Browne P, Chandraratna D, Angood C, et al. Atlas of multiple sclerosis 2013: a growing global problem with widespread inequity. Neurology 2014;83:1022-4

102 Eichler HG, Bloechl-Daum B, Abadie E, et al. Relative efficacy of drugs: an emerging issue between regulatory agencies and third-party payers. Nat Rev Drug Discov 2010;9:277-91.

103 WHO. ICIDH-2: International classification of functioning, disability and health. Geneva, Switzerland: WHO, 2001.

104 National Institute for Health and Care Excellence. Guide to the processes of technology appraisal. 2014 https://www.nice.org.uk/process/pmg19/chapter/ selection-of-technologies 